\title{
Determining of Factors Influencing the Success and Failure of Hospital In- formation System and Their Evaluation Methods: A Systematic Review
}

\author{
Farahnaz Sadoughi ${ }^{1}$, Khalil Kimiafar ${ }^{1,2, *}$, Maryam Ahmadi ${ }^{1}$, Mohammad Taghi Shakeri ${ }^{3}$ \\ ${ }_{2}^{1}$ Department of Health Information Management, School of Health Management and Information Sciences, Iran University of Medical Sciences, Tehran, IR Iran \\ 2 Department of Medical records and Health Information Technology, School of Paramedical Sciences, Mashhad University of Medical Sciences, Mashhad, Iran \\ 3 Department of Community Medicine, Faculty of Medicine, Mashhad University of Medical Sciences, Mashhad, IR Iran \\ *Corresponding Author: Khalil Kimiafar, Department of Medical Records and Health Information Technology, School of Paramedical Sciences, Mashhad University of Medical Sci- \\ ences, Felestin Sq., Mashhad, IR Iran, Tel: +98-5117610111, E-mail: kimiafarkh@mums.ac.ir
}

Received: April 22, 2013; Revised: May 3, 2013; Accepted: May 10, 2013

\begin{abstract}
Background: Nowadays, using new information technology (IT) has provided remarkable opportunities to decrease medical errors, support health care specialist, increase the efficiency and even the quality of patient's care and safety.

objectives: The purpose of this study was the identification of Hospital Information System (HIS) success and failure factors and the evaluation methods of these factors. This research emphasizes the need to a comprehensive evaluation of HISs which considers a wide range of success and failure factors in these systems.

Materials and Methods: We searched for relevant English language studies based on keywords in title and abstract, using PubMed, Ovid Medline (by applying MeSH terms), Scopus, ScienceDirect and Embase (earliest entry to march 17, 2012). Studies which considered success models and success or failure factors, or studied the evaluation models of HISs and the related ones were chosen. Since the studies used in this systematic review were heterogeneous, the combination of extracted data was carried out by using narrative synthesis method. Results: We found 16 articles which required detailed analysis. Finally, the suggested framework includes 12 main factors (functional, organizational, behavioral, cultural, management, technical, strategy, economy, education, legal, ethical and political factors), 67 sub factors, and 33 suggested methods for the evaluation of these sub factors.

Conclusions: The results of the present research indicates that the emphasis of the HIS evaluation moves from technical subjects to human and organizational subjects, and from objective to subjective issues. Therefore, this issue entails more familiarity with more qualitative evaluation methods. In most of the reviewed studies, the main focus has been laid on the necessity of using multi-method approaches and combining methods to obtain more comprehensive and useful results.
\end{abstract}

Keywords: Hospital Information Systems; Health Information Systems; Review Literature

\section{Background}

Nowadays, using new information technology (IT) has provided remarkable opportunities to decrease medical errors, support health care specialist, increase the efficiency and even the quality of patient's care and safety (1, 2 ). On the other hand, there are numerous problems in the scope of IT-based systems in the field of health care; therefore, it causes a deep gap between the positive potential for IT to help health care organizations and their negative impacts. It means that a huge amount of money is invested in health information systems, but a significant portion of this money is wasted for inefficient systems or not implemented ones (3).

Evaluation means "the act of measuring or exploring properties of a health information system (in planning, development, implementation, or operation), the result of which informs a decision to be made concerning that system in a specific context" (4). An evaluation which is carried out based on suitable investment and approved techniques can cause the organization to have a forward movement $(5,6)$. Organizations require a comprehensive evaluation framework, which can help create and develop methods of information system evaluation (7); on the other hand, the identification of methods for information systems evaluation can be possible through the identifying the success and failure factors of these systems (8).

When we talk about success, we should identify what the criteria and parameters used for the evaluation of success are. Success is considered as a dynamic concept (9). Whether the system achieves its intended purpose from its establishment is what we mean by success; moreover, it should be carried out based on an anticipated time table and budget, while the project team and its users are satisfied with the results and this satisfaction should 
be constant (10). Since the information system is complicated and multidimensional, it may succeed or fail in different situations $(11,12)$. These days, due to increasing attention of different organizations to expenses related to the projects of information systems and gaining at least the minimum benefits from them, studying their success or failure has its special importance (13-15). There are various reports presented pertaining to the high rates of failure in IT projects in industrial sector and health care organizations especially in hospitals (3,16-19). Kaplan in his study asserts that the rate of failure in implementation of IT in health care organizations of America is almost 50 percent (20).

Information systems are the combination of different elements, among which the measurement of some elements is easier than that of the others. The evaluation framework which is simply concentrated on elements whose measurement is easier cannot introduce a perfect framework in evaluation of information systems (21). Many case studies have been done, whose results are based on one or a few factors which affect the success of IT-based systems, so it mentions this important point that the findings of such literatures should be put together as a puzzle. In this case, a lot of benefits can be achieved from the significant studies done in this field by using different approaches (22). Just one comprehensive evaluation study can show whether a specific system can be successful in a special place or not. Moreover, each evaluation criterion must be measured through an appropriate method. A perfect evaluation should include all proper success factors $(23,24)$.

Previous researchers have discussed the challenges of the evaluation of health information systems and the problems resulting from lack of unique conceptual framework to guide evaluation researches $(25,26)$. The most significant challenge in evaluation of information systems used in health care is that information systems can influence the improvement of treatment and the patient's health level. Due to this potential influence on the patient's life, more accurate criteria should be applied for the evaluation of these systems $(5,11,27)$. Of course, understanding the effects, results and prerequisites necessary for successful implementation of information technologies in health care require a multi-factor viewpoint (15).

Some success and failure factors have either less or more importance in different information systems (28). The main focus of our study is placed on the HIS, a computer system is designed to support the hospital needs for comprehensive information including patient's information, clinical information and financial management $(29,30)$. The main purpose of this system is improvement the quality of care provided for patients $(31,32)$. Although the integrated HIS leads to more efficient use of sources, it has not resulted in effective service offering, improve- ment quality of care and increased productivity in many countries $(11,33)$. Unfortunately, the measurement methodologies of different effects of these systems have not been improved along with the development of these systems, while the future managers and users of HISs need accurate evaluation of these systems $(11,34)$.

\section{Objectives}

The purpose of this systematic review was the identification of the HIS success and failure factors and the evaluation methods of these factors. This study emphasizes the need to a comprehensive evaluation of HISs which considers a wide range of success and failure factors in these systems.

\section{Materials and Methods}

We searched for relevant English language studies based on keywords in title and abstract, using PubMed, Ovid Medline (by applying MeSH terms), Scopus, ScienceDirect and Embase (earliest entry to March 17, 2012). In addition, we applied methods such as documentation review of relevant agencies (like Statistics and Information Technology Office in Ministry of Health and Medical Education) and databases that provide grey literature (like system for information on grey literature) for publication bias control. Also, searching was supplemented by scanning bibliographies from identified studies. The key journals have been manually searched to find references which may not be found in databases and the list of references. Table 1 represents the used search strategy and Figure 1 shows a flowchart representing the search and way of choosing studies.

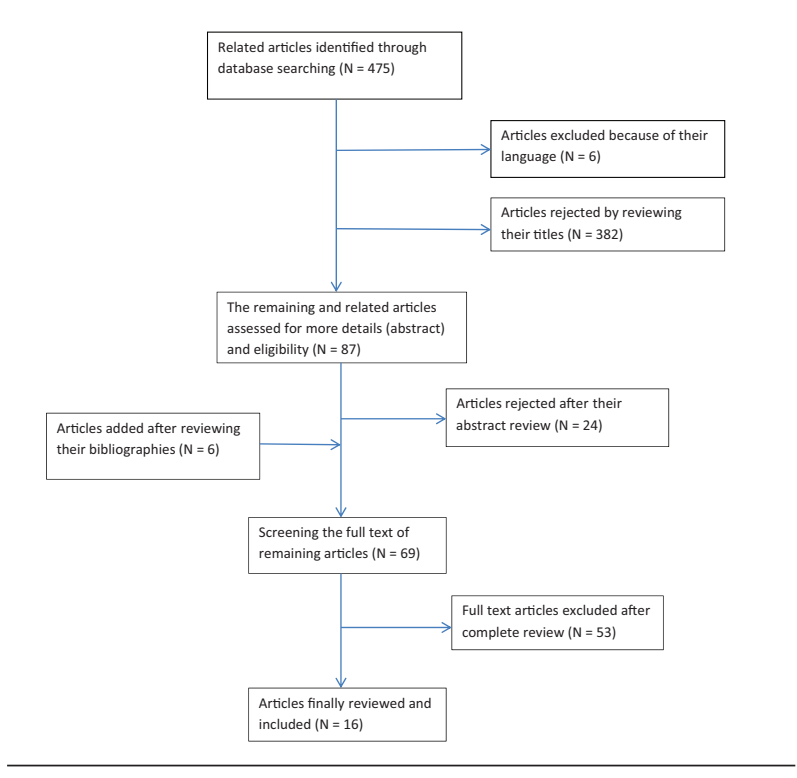


Figure 1. Flowchart of Search and Select the Included Articles in Systematic Review

\begin{tabular}{|c|c|}
\hline Database & Search Strategy \\
\hline \multirow[t]{7}{*}{ Ovid Medline } & 1. exp Hospital Information Systems/ \\
\hline & 2. exp Evaluation Studies as Topic/ \\
\hline & 3.Evaluation Studies.pt. \\
\hline & 4. (fail or failure or success or succeed).ti,ab. \\
\hline & 5. or $/ 2-3$ \\
\hline & 6.1 and 4 and 5 \\
\hline & 7. limit 6 to English language \\
\hline \multicolumn{2}{|l|}{ Pub Med } \\
\hline & 1. "Hospital Information Systems"[Mesh] \\
\hline & $\begin{array}{l}\text { 2. "Evaluation Studies as Topic"[Mesh] OR } \\
\text { "Evaluation Studies" [Publication Type] }\end{array}$ \\
\hline & $\begin{array}{l}\text { 3. fail[tiab] OR failure[tiab] OR success[tiab] } \\
\text { OR succeed[tiab] }\end{array}$ \\
\hline & 4. English[la] \\
\hline & 5. and/1-4 \\
\hline \multicolumn{2}{|l|}{ Embase } \\
\hline & 1. exp Hospital Information Systems/ \\
\hline & 2. exp evaluation/ \\
\hline & 3. (fail or failure or success or succeed).ti, ab. \\
\hline & 4. and/1-3 \\
\hline \multicolumn{2}{|l|}{ Scopus } \\
\hline & 1. TITLE("hospital information system") \\
\hline & $\begin{array}{l}\text { 2. TITLE-ABS-KEY(success OR succeed OR fail } \\
\text { OR failure OR evaluation OR assessment OR } \\
\text { evaluate OR assess) }\end{array}$ \\
\hline & 3.1 and 2 \\
\hline & $\begin{array}{l}\text { 4. SUBJAREA(mult OR medi OR nurs OR vete } \\
\text { OR dent OR heal) }\end{array}$ \\
\hline & 5.3 and 4 \\
\hline \multicolumn{2}{|l|}{ Science Direct } \\
\hline & $\begin{array}{l}\text { 1. TITLE-ABSTR-KEY("hospital information } \\
\text { system") }\end{array}$ \\
\hline & $\begin{array}{l}\text { 2. TITLE-ABSTR-KEY(success OR succeed OR fail } \\
\text { OR failure OR evaluation OR assessment OR } \\
\text { evaluate OR assess) }\end{array}$ \\
\hline & 3.1 and 2 \\
\hline
\end{tabular}

Two reviewers independently examined all titles and abstracts. Cohen's Kappa coefficient was used to measure the inter-rater agreement on the inclusion or exclusion of the articles $(k=0.77)$. The difference between the ideas of the two reviewers was settled by asking the idea of the third reviewer. To control assessment bias, reviewers were blinded about each other's decisions and some information such as the names of journals and authors that could influence their decisions. Studies which considered models and success or failure factors, or studied the evaluation models of the HIS and the related ones were chosen. The studies examining the information systems in a specific area apart from the field of health care and in the field of public health as well as primary care in addition to non-English articles were excluded from the study.

Assessing the quality of qualitative research has attracted much debate and there is little consensus regarding whether quality can or should be assessed in relation to qualitative research (35-37). Since most articles which entered in this study were review articles and data analysis was done on the words and phrases in the articles using meta synthesis, to avoid losing valuable insights that existed in some studies that might be omitted in critical appraisal, we did not assess the quality of the selected studies.

Since the studies used in this systematic review were heterogeneous, the combination of extracted data was carried out by using narrative synthesis method. Finally, the common and varying aspects of the factors and their evaluation methods used in the selected studies were determined. Then these factors and methods were classified in different groups, and a framework was offered for the evaluation of success and failure factors in the HIS.

\section{Results}

Searching the online databases resulted in 475 articles. Initial screening of titles and abstracts rendered 63 articles eligible for further full-text review. Six additional articles were identified by reviewing the bibliographies, yielding a total of 69 articles. Based on reviewing the fulltext of remaining articles, 53 articles were excluded since they did not correspond with the criteria and purpose of this study, and finally 16 articles remained which required detailed analysis. The summaries of findings pertaining to these articles are presented in Table 2. Most selected studies considered factors such as management $(n=11)$, behavioural $(n=15)$, organizational $(n=13)$ and economy $(\mathrm{n}=11$ ) as success factors (Table 3 ). Moreover, some evaluation methods such as interviews $(n=4)$, questionnaires $(n=5)$ and usability measurement methods $(n=7)$ were the most common methods in selected articles (Table 4). 


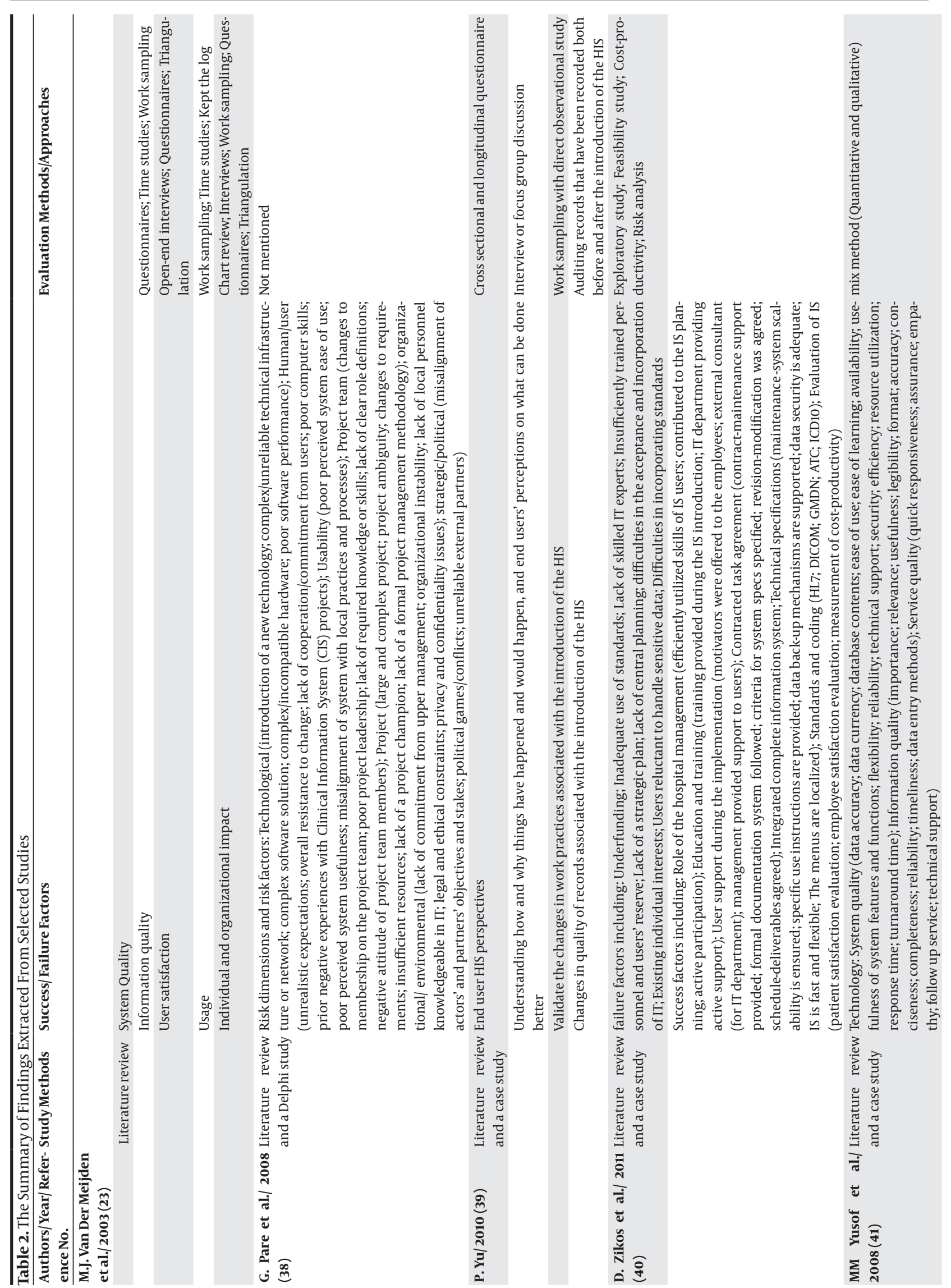




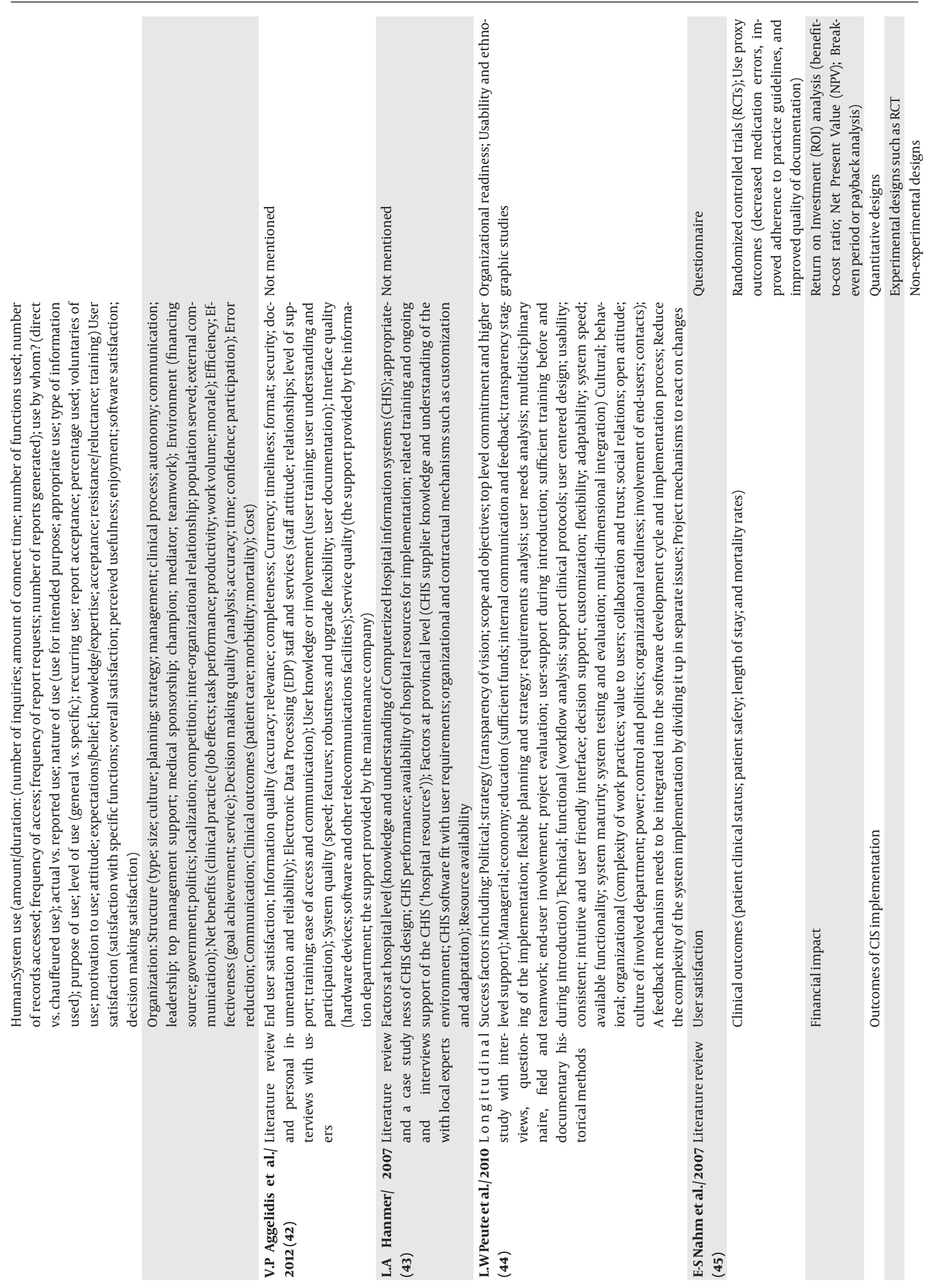



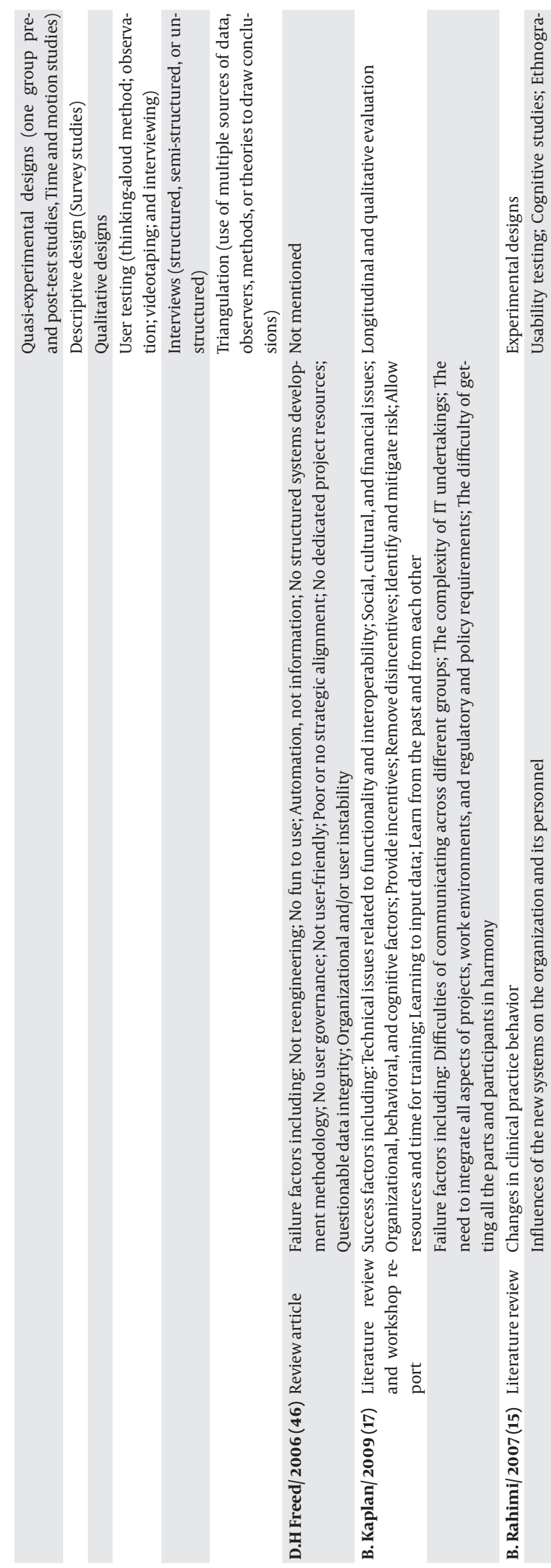

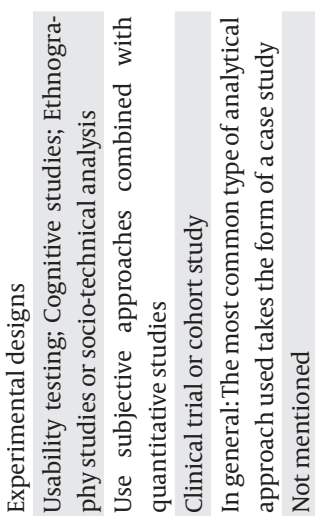

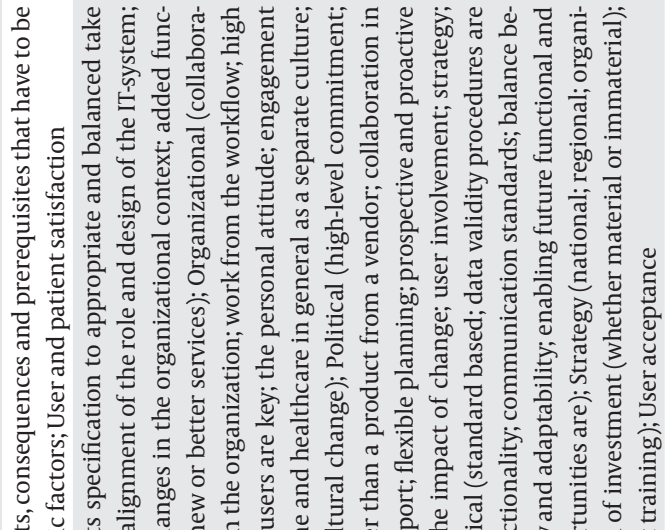

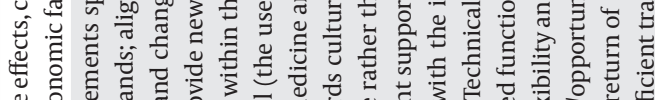

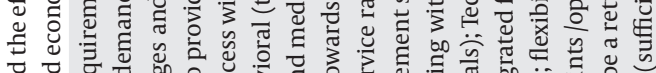

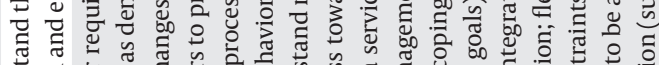

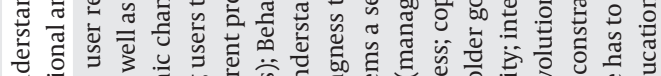

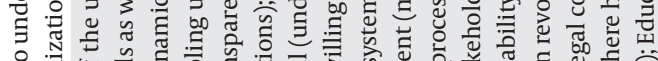

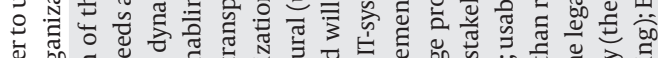

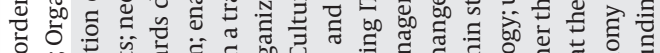

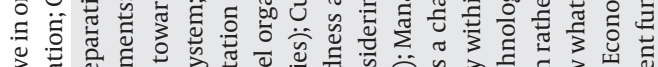

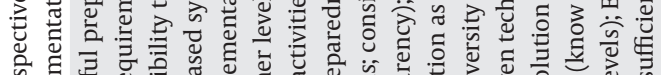

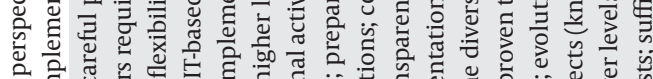

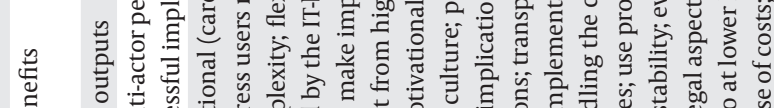

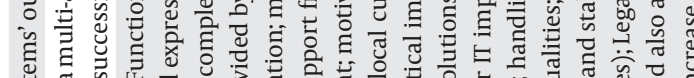

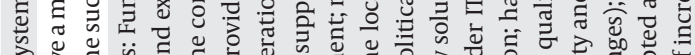

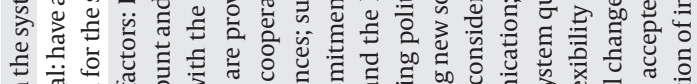

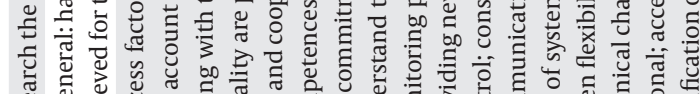

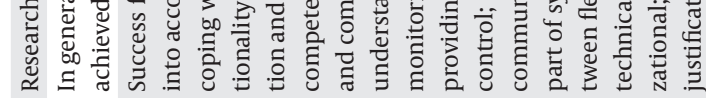

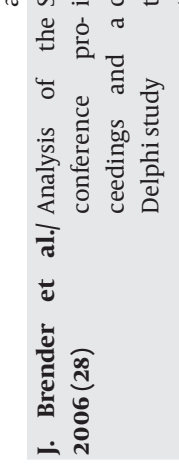




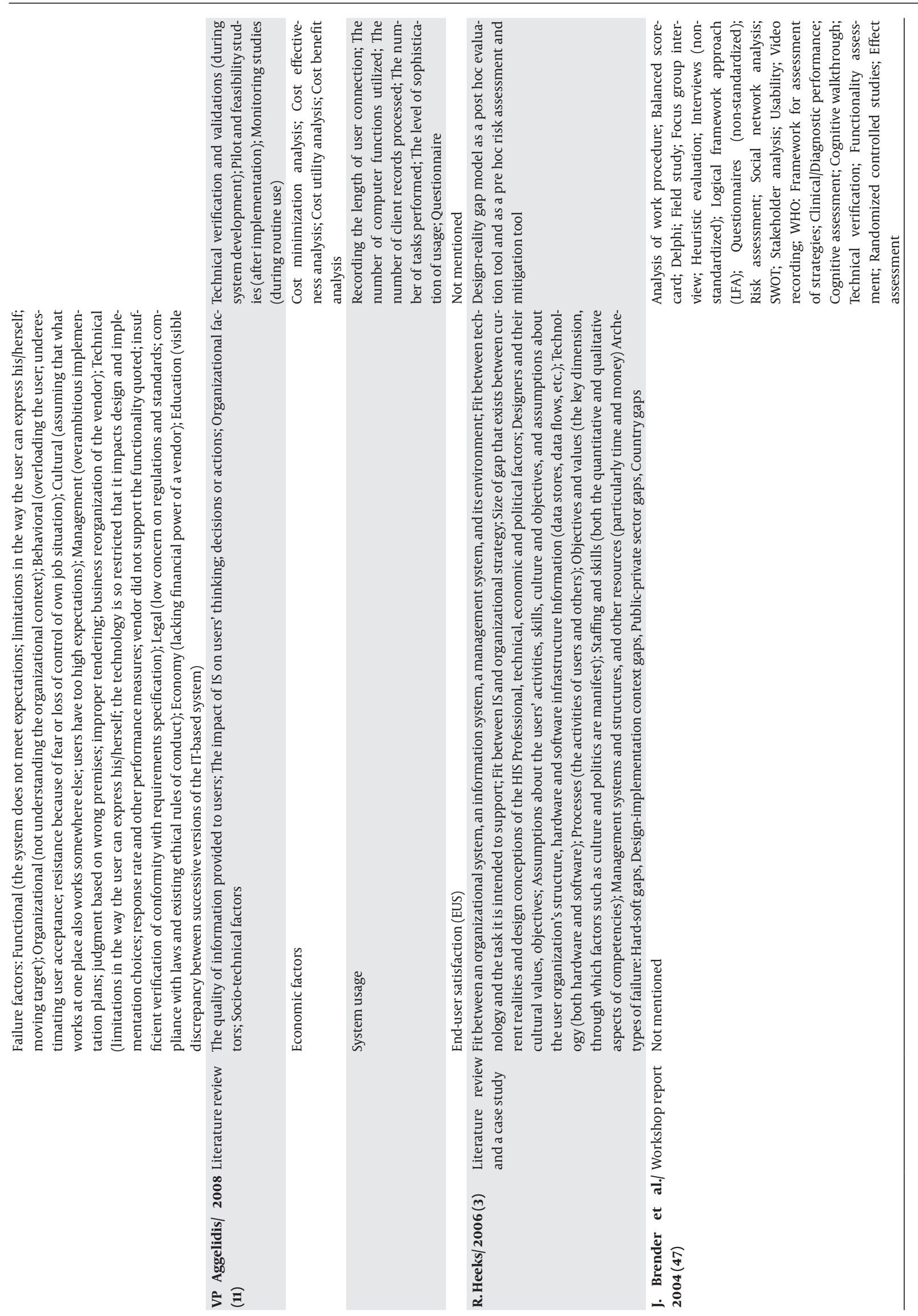


Sadoughi F et al.

Table 3. The HIS Success Factors and Their Frequency in Selected Studies

\begin{tabular}{|c|c|c|c|}
\hline Success Factors & Sub Factors & Frequency (\%) & Reference No. \\
\hline \multirow[t]{6}{*}{ Functional } & Preparation of the user requirements & $4(25)$ & $(38,43,44,28)$ \\
\hline & $\begin{array}{l}\text { Alignment of the role and design of the HIS (Task-technol- } \\
\text { ogy adaption) }\end{array}$ & $4(25)$ & $(3,28,39,41)$ \\
\hline & $\begin{array}{l}\text { Flexibility towards dynamic changes and changes in the } \\
\text { organizational context }\end{array}$ & $4(25)$ & $(28,41,43,44)$ \\
\hline & $\begin{array}{l}\text { Added functionality are provided by the HIS, enabling us- } \\
\text { ers to provide new or better services }\end{array}$ & $3(18.75)$ & $(28,41,44)$ \\
\hline & Improve clinical performance and outcomes & $4(25)$ & $(15,41,44,45)$ \\
\hline & In general & $9(56.25)$ & $(3,15,17,28,38,39,41,43,44)$ \\
\hline \multirow[t]{9}{*}{ Organizational } & Collaboration and cooperation & $6(37.5)$ & $(17,28,38,41,42,44)$ \\
\hline & Participation in decision-making & $3(18.75)$ & $(11,41,44)$ \\
\hline & Work from the workflow & $3(18.75)$ & $(28,44,46)$ \\
\hline & Support from higher level organizations & $3(18.75)$ & $(28,41,44)$ \\
\hline & $\begin{array}{l}\text { Make implementation a transparent process within the } \\
\text { organization }\end{array}$ & $2(12.5)$ & $(28,44)$ \\
\hline & Organizational stability & $3(18.75)$ & $(38,44,46)$ \\
\hline & Rate of hospital independence and authority & $1(6.25)$ & $(41)$ \\
\hline & Organizational capacity for changes & $2(12.5)$ & $(39,44)$ \\
\hline & In general & $13(81.25)$ & $(3,11,15,17,23,28,38,39,41-44,46)$ \\
\hline \multirow[t]{8}{*}{ Behavioral } & User involvement & $4(25)$ & $(28,42,44,46)$ \\
\hline & User engagement and commitment & $6(37.5)$ & $(28,39-42,46)$ \\
\hline & Resistance to changes & $3(18.75)$ & $(28,38,41)$ \\
\hline & User knowledge and skills & $6(37.5)$ & $(3,38,40-43)$ \\
\hline & Stakeholder, user and patient satisfaction & $15(93.75)$ & $(3,11,15,17,23,28,38-46)$ \\
\hline & Motivational activities & $5(31.25)$ & $(17,29,40,41,46)$ \\
\hline & $\begin{array}{l}\text { User acceptance (perceived system ease of use, perceived } \\
\text { system usefulness) }\end{array}$ & $7(43.75)$ & $(29,38-43)$ \\
\hline & In general & $15(93.75)$ & $(3,11,15,17,23,29,38-46)$ \\
\hline \multirow[t]{5}{*}{ Cultural } & Understand health care as a specific culture & $1(6.25)$ & (29) \\
\hline & $\begin{array}{l}\text { Understand the local culture (such as attention to cultural } \\
\text { differences between public and private hospitals as well as } \\
\text { developing and developed countries) }\end{array}$ & $3(18.75)$ & $(3,29,44)$ \\
\hline & $\begin{array}{l}\text { Preparedness and willingness towards cultural change } \\
\text { (professional culture) }\end{array}$ & $1(6.25)$ & (29) \\
\hline & Expectations of users & $3(18.75)$ & $(29,38,41)$ \\
\hline & In general & $6(37.5)$ & $(3,17,29,38,41,44)$ \\
\hline \multirow[t]{9}{*}{ Management } & Managers commitment & $5(31.25)$ & $(29,38,40,41,44)$ \\
\hline & $\begin{array}{l}\text { Formulation and expression of a clear vision for the enter- } \\
\text { prise showing the HIS as part of it }\end{array}$ & $1(6.25)$ & $(44)$ \\
\hline & Setting clear goals and instructions & $3(18.75)$ & $(3,17,44)$ \\
\hline & Flexible planning & $3(18.75)$ & $(29,41,44)$ \\
\hline & Prospective and proactive control & $1(6.25)$ & (29) \\
\hline & Coping with the impact of change & $3(18.75)$ & $(3,28,44)$ \\
\hline & Internal communication and clear feedback & $3(18.75)$ & $(28,41,44)$ \\
\hline & Having a strategy & $4(25)$ & $(28,40,41,44)$ \\
\hline & Handling the diversity within stakeholder goals & $2(12.5)$ & $(28,38)$ \\
\hline
\end{tabular}




\begin{tabular}{|c|c|c|c|}
\hline & Using formal project management methodology & $2(12.5)$ & $(38,46)$ \\
\hline & $\begin{array}{l}\text { Dedicate, availability and prioritize of competitive hospital } \\
\text { resources (human, financial and physical resources and } \\
\text { time) }\end{array}$ & $6(37.5)$ & $(3,17,38,41,43,44)$ \\
\hline & Identify and mitigate risk (risk management) & $1(6.25)$ & (17) \\
\hline & Consider IT implementation as a change process & $1(6.25)$ & $(28)$ \\
\hline & Understanding socio-technical nature of HISs & $3(18.75)$ & $(11,15,17)$ \\
\hline & $\begin{array}{l}\text { Regular evaluations and using their results at different } \\
\text { stages of HIS life cycle }\end{array}$ & $2(12.5)$ & $(40,44)$ \\
\hline & In general & $11(68.75)$ & $(3,11,15,17,28,38,40,41,43,44,46)$ \\
\hline \multirow{14}{*}{$\begin{array}{l}\text { Technical (system } \\
\text { quality, information } \\
\text { quality and service } \\
\text { quality) }\end{array}$} & Integration with Legacy system & $3(18.75)$ & $(28,40,44)$ \\
\hline & Interoperability and Interconnectivity & $2(12.5)$ & $(17,42)$ \\
\hline & Usability & $7(43.75)$ & $(28,38,40-42,44,46)$ \\
\hline & Balance between flexibility and stability of IT & $2(12.5)$ & $(28,40)$ \\
\hline & Reliable technical infrastructure or network, & $2(12.5)$ & $(3,38)$ \\
\hline & Complexity of the system & $3(18.75)$ & $(17,28,38)$ \\
\hline & $\begin{array}{l}\text { Information quality (relevancy, usefulness, completeness, } \\
\text { etc.) }\end{array}$ & $8(50)$ & $(3,11,15,23,28,41,42,46)$ \\
\hline & Response time (system speed) & $5(31.25)$ & $(28,40-42,44)$ \\
\hline & System security & $3(18.75)$ & $(40-42)$ \\
\hline & $\begin{array}{l}\text { Service quality (the support provided by the information } \\
\text { department, the support provided by the maintenance } \\
\text { company) }\end{array}$ & $5(31.25)$ & $(28,40-43)$ \\
\hline & Quality of user documentation & $2(12.5)$ & $(40,42)$ \\
\hline & $\begin{array}{l}\text { Flexibility and adoptability, enabling future functional and } \\
\text { technical changes }\end{array}$ & $5(31.25)$ & $(28,38,41,42,44)$ \\
\hline & Using proper standards, coding and nomenclature & $1(6.25)$ & $(40)$ \\
\hline & In general & $13(81.25)$ & $(3,11,15,17,23,28,38,40-44,46)$ \\
\hline \multirow[t]{4}{*}{ Strategy } & National, regional, organizational & $2(12.5)$ & $(28,41)$ \\
\hline & Accepted also at lower levels & $1(6.25)$ & $(28)$ \\
\hline & $\begin{array}{l}\text { Alignment between system strategies and hospital strate- } \\
\text { gies }\end{array}$ & $3(18.75)$ & $(3,38,46)$ \\
\hline & In general & $7(43.75)$ & $(3,28,38,40,41,44,46)$ \\
\hline \multirow[t]{4}{*}{ Economy } & Return on investment (material or immaterial) & $4(25)$ & $(15,28,40,41)$ \\
\hline & Justification of increase of costs & $4(25)$ & $(15,28,41,45)$ \\
\hline & Sufficient funding & $4(25)$ & $(28,40,41,44)$ \\
\hline & In general & $11(68.75)$ & $(3,11,15,17,28,40,41,43-46)$ \\
\hline \multirow[t]{3}{*}{ Education } & $\begin{array}{l}\text { Sufficient training to make the best out of the daily opera- } \\
\text { tion }\end{array}$ & $3(18.75)$ & $(17,28,40)$ \\
\hline & $\begin{array}{l}\text { Sufficient training to provide an understanding of its limi- } \\
\text { tations and future potentials }\end{array}$ & $1(6.25)$ & (17) \\
\hline & In general & $7(43.75)$ & $(17,28,40-44)$ \\
\hline \multirow[t]{3}{*}{ Legal } & Compliance with legal requirements & $1(6.25)$ & $(28)$ \\
\hline & Know what the legal constraints/opportunities are & $1(6.25)$ & $(28)$ \\
\hline & In general & $2(12.5)$ & $(28,38)$ \\
\hline
\end{tabular}




\begin{tabular}{llll} 
Ethical & $\begin{array}{l}\text { Compliance with existing ethical rules in affairs manage- } \\
\text { ment }\end{array}$ & $1(6.25)$ & (28) \\
& Privacy and confidentiality & $1(6.25)$ & $(38)$ \\
\hline Political & In general & $3(18.75)$ & $(28,38,41)$ \\
& Political games/conflicts & $2(12.5)$ & $(28,38)$ \\
& Willingness towards investment on IT systems & $1(6.25)$ & $(28)$ \\
& Reliable external partners & $2(12.5)$ & $(28,38)$ \\
\hline
\end{tabular}

\begin{tabular}{|c|c|c|}
\hline Evaluation Methods & Frequency (\%) & Reference No. \\
\hline Analysis of work procedure & $1(6.25)$ & $(47)$ \\
\hline Stakeholder analysis & $1(6.25)$ & $(47)$ \\
\hline Organizational readiness & $1(6.25)$ & $(44)$ \\
\hline Framework for assessment of strategies & $1(6.25)$ & $(47)$ \\
\hline Thinking-aloud & $2(12.5)$ & $(15,45)$ \\
\hline Cognitive assessment & $2(12.5)$ & $(15,47)$ \\
\hline Cognitive walkthrough & $2(12.5)$ & $(15,47)$ \\
\hline Heuristic evaluation & $2(12.5)$ & $(15,47)$ \\
\hline Balanced scorecard & $1(6.25)$ & $(47)$ \\
\hline Risk assessment & $3(18.75)$ & $(3,40,47)$ \\
\hline Focus group interview & $2(12.5)$ & $(40,47)$ \\
\hline Delphi & $1(6.25)$ & $(47)$ \\
\hline Social network analysis & $2(12.5)$ & $(15,47)$ \\
\hline Randomized controlled studies & $3(18.75)$ & $(15,45,47)$ \\
\hline $\begin{array}{l}\text { Use proxy outcomes (decreased medication errors, improved adherence to practice } \\
\text { guidelines, and improved quality of documentation) }\end{array}$ & $2(12.5)$ & $(45,47)$ \\
\hline Interviews & $4(25)$ & $(23,39,45,47)$ \\
\hline Questionnaires & $5(31.25)$ & $(11,23,39,45,47)$ \\
\hline Functionality assessment & $1(6.25)$ & $(47)$ \\
\hline Design-reality gap model & $1(6.25)$ & (3) \\
\hline Logical framework approach (LFA) & $1(6.25)$ & $(47)$ \\
\hline Work sampling & $2(12.5)$ & $(23,39)$ \\
\hline SWOT & $1(6.25)$ & $(47)$ \\
\hline Studying the existing documents and Chart review & $2(12.5)$ & $(23,39)$ \\
\hline Technical verification & $2(12.5)$ & $(11,47)$ \\
\hline Video recording & $3(18.75)$ & $(11,45,47)$ \\
\hline Time studies & $2(12.5)$ & $(23,45)$ \\
\hline Kept the log & $2(12.5)$ & $(11,23)$ \\
\hline Effect assessment & $1(6.25)$ & $(47)$ \\
\hline Field study & $1(6.25)$ & $(47)$ \\
\hline Cost minimization analysis & $1(6.25)$ & (11) \\
\hline Cost effectiveness analysis & $3(18.75)$ & $(11,40,45)$ \\
\hline Cost utility analysis & $3(18.75)$ & $(11,40,45)$ \\
\hline Cost benefit analysis & $3(18.75)$ & $(11,40,45)$ \\
\hline
\end{tabular}




\section{Discussion}

The results of the present research indicate that the emphasis of HISs evaluation moves from technical subjects to human and organizational subjects and from objective to subjective issues. Therefore, this issue entails more familiarity with more qualitative evaluation methods.

It has been proved that the application of HISs can create basic changes in culture, policy and authority, which link professional groups to one another in an organization. However, these basic subjects have not been identified in many of success models. These issues result in the inability of these models to interpret some cases of failure (39). Many studies published about the success of information systems have been carried out by focusing on the model of Delone and McLean $(48,49)$. Since in this model some important factors have not been considered, the mentioned studies cannot present a comprehensive model in this field. For instance, they deal with supporting the top managers and the involvement of users, and point out that these factors can influence the level of success, but these variables are not considered in this model. Moreover, other factors like culture and organizational characteristics are not considered in this model. The changes of procedures and culture are among the obstacles which are reported in widespread use of health care information systems (41). Other studies emphasized on organizational and management factors such as management commitment, a champion and his/her characteristics $(28,38,41,51,52)$.

The findings indicate that, among different factors of success, user satisfaction to measure HISs success is of special significance $(3,11,15,17,23,28,38-46)$. This factor is probably the most widespread factor used in measurement of success $(11,41,42)$. Even though some researchers may doubt about the reliability and appropriateness of using the user satisfaction to measure the success of information systems $(52,53)$, the researches which have been carried out, have proved that satisfaction is a useful criterion to measure the success of the system (11, 32, $54,55)$. However, in the field of health care information systems, only four percent of researches have used the criterion of the influence of user satisfaction, whereas this rate reaches almost 20 percent in the researches of information systems (56). The findings show that, in published literatures, special attention has been paid to the economy factors and their evaluation $(3,11,15,17,28$, $38,40,41,43-46)$. On the other hand, when the efficiency of investment in IT is studied, some problems manifest themselves as follows (11):

1- The expenditures are mostly indirect, so their calculation is difficult

2- The benefits and organizational impacts are often intangible, so their realization may take a long time

In spite of these problems, findings show that there are appropriate and verified methods for evaluating economy aspects which provide useful information in this area. The other point which seems noticeable about the success factors of the HIS refers to two of selected articles indicating that the evaluation of HISs is one of the success factors $(40,44)$. We believe that the quality and quantity of evaluations and using their results at different stages of the HIS life cycle can be an influential and significant factor in the success of such systems, and this factor can be studied through methods like interviews and studying the existing documents.

The findings reveal that, among the suggested methods for the evaluation of success or failure factors of HISs, using questionnaires $(11,23,39,45,47)$ and interviews (23, $39,45,47)$ are more emphasized. Questionnaires are the best approved method for the evaluation of personal opinion, perception and attitude which is widely used in information systems and health researches. A comprehensive interview and focus group interview are effective on understanding how and why events have happened or will occur and on the perception of users about how affairs can be done more efficiently (39).

Among the evaluation methods extracted for this research, some methods are based on the retrospective nature (like functionality assessment). The other kinds such as balanced scorecard and delphi methods might present a guideline for planning and revision HISs, which provide formative evaluation (57). Some methods may not meet the specific information needs in the related field completely, but can be used as valuable supportive means in the field of evaluation. As the symptoms of a disease comprise a part of the pattern of that disease all these methods present a pattern to show the success or failure (8). The presented methods are adapted from different sciences including psychology, social science, computer and health informatics sciences. Applying adapted evaluation methods requires methodological skills, discipline, innovation and flexibility to adapt the chosen method with the intended case, its situation and specifically information needs $(8,24)$.

The major limitations of this study are that some selected studies deal with only success and failure factors (28, $38,42,43,46)$, or focused on evaluation methods (47), but, due to the significance of these studies, they are considered and reviewed in this research. In addition, among the extracted factors, there were some factors which could be placed in different groups and several discussion sessions took place to choose the most appropriate category for each factor. Another limitation is that only the articles written in English were selected; therefore, there might be some noteworthy articles in this field published in other languages.

In most of the reviewed articles, the main focus has been laid on the necessity of using multi-method approaches and combining methods to obtain more comprehensive and useful results. The integrating of different methods can be beneficial to find an inclusive answer to evaluation questions. The integrity of supplementary methods, data 
sources, theories and observers are studied under the term of triangulation (58). The combination of qualitative data gathering approaches (such as observations and interviews) and quantitative data gathering approaches (such as questionnaires and work sampling) provides a good opportunity through triangulation to improve the quality of results (59).

Finally, in this research, the extraction of key concepts of each study was carried out through applying meta synthesis, and such concepts were put together and clas- sified, then the suggested framework was formed to evaluate the HIS success [ Table 5 ]. This framework includes 12 main factors, 67 sub factors, and 33 suggested methods for the evaluation of these sub factors. One can determine the appropriate method based on this information and with a general review of the listed methods and factors, or he/she can create better and more comprehensive methods based on his/her information needs. Of course, more attempts and investigations are still necessary to be done in this field.

Table 5. The HIS Success Factors and Their Suggested Evaluation Methods

\begin{tabular}{|c|c|}
\hline Success Factors & Sub Factors \\
\hline \multirow[t]{5}{*}{ Functional } & Preparation of the user requirements \\
\hline & $\begin{array}{l}\text { Alignment of the role and design of the HIS (Task- } \\
\text { technology adaption) }\end{array}$ \\
\hline & $\begin{array}{l}\text { Flexibility towards dynamic changes and changes in } \\
\text { the organizational context }\end{array}$ \\
\hline & $\begin{array}{l}\text { Added functionality are provided by the HIS, enablin } \\
\text { users to provide new or better services }\end{array}$ \\
\hline & Improve clinical performance and outcomes \\
\hline
\end{tabular}

\section{Evaluation Methods}

Analysis of work procedure, Stakeholder analysis, Organizational readiness, Framework for assessment of strategies

Thinking-aloud, Cognitive assessment, Cognitive walkthrough, Heuristic evaluation, Analysis of work procedure

Organizational readiness, Balanced scorecard, Risk assessment

Focus group interview, Delphi, Social network analysis, Stakeholder analysis

Randomized controlled studies, Use proxy outcomes (decreased medication errors, improved adherence to practice guidelines, and improved quality of documentation)

\begin{tabular}{|c|c|c|}
\hline \multirow[t]{8}{*}{ Organizational } & Collaboration and cooperation & Social network analysis, Stakeholder analysis \\
\hline & Participation in decision-making & Focus group interview \\
\hline & Work from the workflow & Social network analysis \\
\hline & Support from higher level organizations & Stakeholder analysis, Interviews (non-standardized) \\
\hline & $\begin{array}{l}\text { Make implementation a transparent process within } \\
\text { the organization }\end{array}$ & $\begin{array}{l}\text { Focus group interview, Social network analysis, Stake- } \\
\text { holder analysis }\end{array}$ \\
\hline & Organizational stability & Social network analysis, Organizational readiness \\
\hline & Rate of hospital independence and authority & Interviews \\
\hline & Organizational capacity for changes & Organizational readiness \\
\hline \multirow[t]{7}{*}{ Behavioral } & User involvement & $\begin{array}{l}\text { Social network analysis, Stakeholder analysis, Focus } \\
\text { group interview, Questionnaires }\end{array}$ \\
\hline & User engagement and commitment & $\begin{array}{l}\text { Focus group interview, Social network analysis, Stake- } \\
\text { holder analysis }\end{array}$ \\
\hline & Resistance to changes & Organizational readiness \\
\hline & User knowledge and skills & Focus group interview, Questionnaires \\
\hline & Stakeholder, user and patient satisfaction & Focus group interview, Questionnaires \\
\hline & Motivational activities & Focus group interview, Personal interviews \\
\hline & $\begin{array}{l}\text { User acceptance (perceived system ease of use, per- } \\
\text { ceived system usefulness) }\end{array}$ & Focus group interview, Questionnaires \\
\hline \multirow[t]{3}{*}{ Cultural } & Understand health care as a specific culture & Analysis of work procedure \\
\hline & $\begin{array}{l}\text { Understand the local culture (such as attention to cul- } \\
\text { tural differences between public and private hospitals } \\
\text { as well as developing and developed countries) }\end{array}$ & $\begin{array}{l}\text { Analysis of work procedure, Functionality assessment, } \\
\text { Design-reality gap model }\end{array}$ \\
\hline & $\begin{array}{l}\text { Preparedness and willingness towards cultural change } \\
\text { (professional culture) }\end{array}$ & Organizational readiness \\
\hline
\end{tabular}




\section{Expectations of users}

$\begin{array}{ll}\text { Management } & \text { Managers commitment } \\ & \text { Formulation and expression of a clear vision for the } \\ \text { enterprise showing the HIS as part of it } & \\ & \text { Setting clear goals and instructions }\end{array}$

Flexible planning

Prospective and proactive control

Coping with the impact of change

Internal communication and clear feedback

Having a strategy

Handling the diversity within stakeholder goals

Using formal project management methodology

Dedicate, availability and prioritize of competitive hospital resources (human, financial and physical resources and time)

Identify and mitigate risk (risk management)

Consider IT implementation as a change process

Understanding socio-technical nature of HISs

Regular evaluations and using their results at different stages of HIS life cycle

Technical (system qual-

ity, information quality and service quality)

Interoperability and Interconnectivity

Usability

Balance between flexibility and stability of IT

Reliable technical infrastructure or network,

Complexity of the system

Information quality (relevancy, usefulness, completeness, etc.)

Response time (system speed)

System security

Service quality (the support provided by the information department, the support provided by the maintenance company)

Quality of user documentation

Flexibility and adoptability, enabling future functional Technical verification and technical changes

Using proper standards, coding and nomenclature National, regional, organizational

Accepted also at lower levels

Alignment between system strategies and hospital strategies
Thinking-aloud, Questionnaires, Interviews

Focus group interview

Logical framework approach (LFA)

Balanced scorecard, Framework for assessment of strategies

Balanced scorecard, Framework for assessment of strategies

Documents and chart review

Logical framework approach (LFA)

Organizational readiness, Work sampling

Social network analysis

Framework for assessment of strategies

Stakeholder analysis, Organizational readiness

Analysis of work procedure, Balanced scorecard, Framework for assessment of strategies

Risk assessment, SWOT assessment

Risk assessment, Design-reality gap model

Analysis of work procedure, Framework for assessment of strategies

Interviews, Questionnaires, Delphi review

Technical verification

\section{Technical verification}

Cognitive assessment, Cognitive walkthrough, Heuristic evaluation, Video recording, Thinking-aloud, Work sampling, Time studies, Kept the log

Organizational readiness against change

Technical verification

Technical verification

Chart review, Questionnaires

Questionnaires, Time and motion studies, Work sampling

Technical verification

Review of contracted task agreement and chart review, Questionnaires, Interviews

Technical verification

Framework for assessment of strategies

Focus group interview

Framework for assessment of strategies 


\begin{tabular}{|c|c|c|}
\hline \multirow[t]{3}{*}{ Economy } & Return on investment (material or immaterial) & $\begin{array}{l}\text { Delphi, Effect assessment, Field study, Cost minimiza- } \\
\text { tion analysis, Cost effectiveness analysis, Cost utility } \\
\text { analysis, Cost benefit analysis }\end{array}$ \\
\hline & Justification of increase of costs & $\begin{array}{l}\text { Delphi, Cost effectiveness analysis, Cost utility analysis, } \\
\text { Cost benefit analysis }\end{array}$ \\
\hline & Sufficient funding & $\begin{array}{l}\text { Delphi, Cost effectiveness analysis, Cost utility analysis, } \\
\text { Cost benefit analysis }\end{array}$ \\
\hline \multirow[t]{2}{*}{ Education } & $\begin{array}{l}\text { Sufficient training to make the best out of the daily } \\
\text { operation }\end{array}$ & Functionality assessment, Work sampling, Time studies \\
\hline & $\begin{array}{l}\text { Sufficient training to provide an understanding of its } \\
\text { limitations and future potentials }\end{array}$ & Focus group interview \\
\hline \multirow[t]{2}{*}{ Legal } & Compliance with legal requirements & Field study, Review of legal documents \\
\hline & Know what the legal constraints/opportunities are & SWOT, Interviews \\
\hline \multirow[t]{2}{*}{ Ethical } & $\begin{array}{l}\text { Compliance with existing ethical rules in affairs man- } \\
\text { agement }\end{array}$ & Focus group interview \\
\hline & Privacy and confidentiality & Focus group interview, Chart review \\
\hline \multirow[t]{3}{*}{ Political } & Political games/conflicts & SWOT, Delphi \\
\hline & Willingness towards investment on IT systems & Interviews, Questionnaires \\
\hline & Reliable external partners & $\begin{array}{l}\text { Chart review and review of contracts as well as history of } \\
\text { partners activities }\end{array}$ \\
\hline
\end{tabular}

\section{Acknowledgements}

This study was part of a PhD. dissertation supported by Iran University of Medical Sciences (grant No: IUMS/ SHMIS-1390/460)

\section{Financial Disclosure}

There is no financial disclosure.

\section{Funding Support}

There is no funding or support.

\section{Authors' Contributions}

Kimiafar carried out the design and coordinated the study, participated in most of the experiments and prepared the manuscript. Dr. Sadoughi and Dr. Ahmadi provide assistance in the design of the study, coordinated and carried out all the research sections and participated in manuscript preparation. Dr. Shakeri provided assistance for methodology design and all study sections. All authors have read and approved the content of the manuscript.

\section{References}

1. Low C, Hsueh Chen Y. Criteria for the evaluation of a cloud-based hospital information system outsourcing provider. J Med Syst. 2012;36(6):3543-53.

2. Sheikhtaheri A, Sadoughi F, Ahmadi M, Moghaddasi H. A framework of a patient safety information system for Iranian hospitals: lessons learned from Australia, England and the US. Int J Med
Inform. 2013;82(5):335-44

3. Heeks R. Health information systems: failure, success and improvisation. Int J Med Inform. 2006;75(2):125-37.

4. Ammenwerth E, Brender J, Nykanen P, Prokosch HU, Rigby M, Talmon J, et al. Visions and strategies to improve evaluation of health information systems. Reflections and lessons based on the HIS-EVAL workshop in Innsbruck. Int J Med Inform. 2004;73(6):479-91.

5. Rigby M. Evaluation--the Cinderella science of ICT in health Yearb Med Inform. 2006:114-20.

6. Sadoughi Farahnaz, Aminpour Farzaneh. A Review on the Evaluation Methods of Health Information Systems. Iran J Med Edu. 2011;10(5):1077-1086.

7. Ozkan Sevgi, Baykal Nazife, Sincan Murat. Process-Based Evaluation of Hospital Information Systems: Application of an Information System Success Model (PRISE) in the Healthcare Domain. Health Information Systems: Concepts, Methodologies, Tools, and Applications.. Hershey, PA, USA: IGI Global; 2012. p. 339-355.

8. Brender J. Evaluation methods to monitor success and failure factors in health information systems development. In: Kushniruk AW, Borycki E editors. Human, social, and organizational aspects of health information systems.. New York: IGI; 2008. p.180-201.

9. Berg M. Implementing information systems in health care organizations: myths and challenges. Int J Med Inform. 2001;64(23):143-56.

10. Fortune J, Peters G. Information systems : achieving success by avoiding failure.Chichester, England: John Wiley \& Sons; 2005.

11. Aggelidis VassiliosP, Chatzoglou ProdromosD. Methods for evaluating hospital information systems: a literature review. $\mathrm{Eu}$ roMed J Busin. 2008;3(1):99-118.

12. Wateridge John. How can IS/IT projects be measured for success? Int J Project Manag. 1998;16(1):59-63.

13. Delpierre C, Cuzin L, Fillaux J, Alvarez M, Massip P, Lang T. A systematic review of computer-based patient record systems and quality of care: more randomized clinical trials or a broader approach? Int J Qual Health Care. 2004;16(5):407-16.

14. Kaplan B, Shaw NT. Future directions in evaluation research people, organizational, and social issues. Methods Inf Med. 2004;43(3):215-31.

15. Rahimi B, Vimarlund V. Methods to evaluate health information systems in healthcare settings: a literature review. J Med Syst. 2007;31(5):397-432.

16. Jones Capers. Patterns of large software systems: failure and suc- 
cess. Computer. 1995;28(3):86-87.

17. Kaplan B, Harris-Salamone KD. Health IT success and failure: recommendations from literature and an AMIA workshop. J Am Med Inform Assoc. 2009;16(3):291-9.

18. Wears RL, Berg M. Computer technology and clinical work: still waiting for Godot. JAMA. 2005;293(10):1261-3.

19. Sadoughi F, Sheikhtaheri A, Meidani Z ShahmoradiL. Management information system (concept, structure, development and evaluation).Tehran: Jafari; 2011.

20. Kaplan B. Culture counts: how institutional values affect computer use. MD Comput. 2000;17(1):23-6.

21. Perera R, Dowell T, Crampton P, Kearns R. Panning for gold: an evidence-based tool for assessment of performance indicators in primary health care. Health Policy. 2007;80(2):314-27.

22. Brender Jytte. Evaluation Methods to Monitor Success and Failure Factors in Health Information System's Development. Health Information Systems: Concepts, Methodologies, Tools, and Applications.. Hershey, PA, USA: IGI Global; 2010. p. 605-626.

23. Van Der Meijden MJ, Tange HJ, Troost J, Hasman A. Determinants of success of inpatient clinical information systems: a literature review. J Am Med Inform Assoc. 2003;10(3):235-43.

24. Sadoughi F, Ghazisaeidi M, Meraji M, Kimiafar K, Ramezanghorbani N. Health information management technology.Tehran: Jafari; 2011

25. Ammenwerth E, Graber S, Herrmann G, Burkle T, Konig J. Evaluation of health information systems-problems and challenges. Int J Med Inform. 2003;71(2-3):125-35.

26. Kaplan B. Evaluating informatics applications--some alternative approaches: theory, social interactionism, and call for methodological pluralism. Int J Med Inform. 2001;64(1):39-56.

27. Kaplan B, Shaw NT. People, organizational, and social issues: Evaluation as an exemplar. Yearbook Med Info. 2002;2.

28. Brender J, Ammenwerth E, Nykanen P, Talmon J. Factors influencing success and failure of health informatics systems--a pilot Delphi study. Methods InfMed. 2006;45(1):125-36.

29. Shortliffe EH, Cimino JJ. Biomedical Informatics: Computer Applications in Health Care and Biomedicine (Health Informatics).Secaucus, NJ: Springer-Verlag New York, Inc.; 2006.

30. Moradi Gholamreza, Sarbaz Masoumeh, Kimiafar Khalil, Shafiei Naser, Setayesh Yousof. The role of hospital information system on Dr Sheikh Hospital performance promotion in Mashhad. Health Info ManagJ. 2009;5(2).

31. Bates DW, Cohen M, Leape LL, Overhage JM, Shabot MM, Sheridan $\mathrm{T}$. Reducing the frequency of errors in medicine using information technology. J Am Med Inform Assoc. 2001;8(4):299-308.

32. Vafaee A, Vahedian M, Esmaeily H, Kimiafar K. Views of Users towards the Quality of Hospital Information System in Training Hospitals. J Res Health Sci. 2010;10(1):47-53.

33. Ahmadi M, Barabadi M, Kamkar Haghighi M. Evaluation of Hospital Information Systems in the Medical Records. Health Info Manag J. 2010;7(1):48-55.

34. Farzandipour Mehrdad, Sadoughi Farahnaz, Meidani Zahra. Hospital Information Systems User Needs Analysis: A Vendor Survey. J Health Informat Dev Countries. 2011;5(1).

35. Thomas J, Harden A. Methods for the thematic synthesis of qualitative research in systematic reviews. BMC Med Res Methodol. 2008;8:45.

36. Beck CT. Caring within nursing education: a metasynthesis. $J$ Nurs Educ. 2001;40(3):101-9.

37. Thorne S, Jensen L, Kearney MH, Noblit G, Sandelowski M. Qualitative metasynthesis: reflections on methodological orientation and ideological agenda. Qual Health Res. 2004;14(10):1342-65.

38. Pare G, Sicotte C, Jaana M, Girouard D. Prioritizing the risk factors influencing the success of clinical information system projects. A Delphi study in Canada. Methods Inf Med. 2008;47(3):251-9.
39. Yu P. A multi-method approach to evaluate health information systems. Stud Health Technol Inform. 2010;160(Pt 2):1231-5.

40. Zikos D, Mitsios A, Mantas J. Assessment of hospital information systems implementation: a case study. Stud Health Technol Inform. 2011;165:123-8.

41. Yusof MM, Kuljis J, Papazafeiropoulou A, Stergioulas LK. An evaluation framework for Health Information Systems: human, organization and technology-fit factors (HOT-fit). Int J Med Inform. 2008;77(6):386-98.

42. Aggelidis VP, Chatzoglou PD. Hospital information systems: measuring end user computing satisfaction (EUCS). J Biomed Inform. 2012;45(3):566-79.

43. Hanmer LA, Roode JD, Isaacs S. Modelling the effect of limited or vulnerable resources on the use of computerised hospital information systems (CHISs) in South Africa. Stud Health Technol Inform. 2007;130:299-309.

44. Peute LW, Aarts J, Bakker PJ, Jaspers MW. Anatomy of a failure: a sociotechnical evaluation of a laboratory physician order entry system implementation. Int J Med Inform. 2010;79(4):e58-70.

45. Nahm ES, Vaydia V, Ho D, Scharf B, Seagull J. Outcomes assessment of clinical information system implementation: a practical guide. Nurs Outlook. 2007;55(6):282-288.

46. Freed DH. Certain death: ten predictors of hospital information system failure. Health Care Manag (Frederick). 2006;25(1):26-33.

47. Brender Jytte. Handout: Medinfo 2004 Workshop:"Good Evaluation of Health informatics Applications". 2004.

48. DeLone WilliamH, McLean EphraimR. Information systems success: the quest for the dependent variable. Inf Sys Res. 1992;3(1):60-95.

49. Delone WilliamH. The DeLone and McLean model of information systems success: a ten-year update. J Manag Inf Sys. 2003;19(4):930.

50. Moghaddasi H, Sheikhtaheri A. CEO is a vision of the future role and position of CIO in healthcare organizations. J Med Syst. 2010;34(6):1121-8.

51. Shahmoradi L, Ahmadi M, Haghani H. Determining the most important evaluation indicators of healthcare information systems and suggested model. J Health Admin. 2007;10(28):15-24.

52. Galletta DennisF, Lederer AlbertL. Some cautions on the measurement of user information satisfaction*. Decision Sciences. 1989;20(3):419-434

53. Melone NancyPaule. A theoretical assessment of the user-satisfaction construct in information systems research. Manag Scie. 1990;36(1):76-91.

54. Ahmadi M, Shahmoradi L, Barabadi M, Hoseini AF. A survey of usability of hospital information systems from the perspective of nurses, department secretaries, and paraclinic users in selected hospitals: 2009. J Health Admin. 2011;14(44):Pe11-Pe20.

55. Sadoughi Farahnaz, Khoshkam Masoumeh, Farahi SayedehRaziyeh. Usability Evaluation of Hospital Information Systems in Hospitals Affiliated with Mashhad University of Medical Sciences, Iran. Director General. 2012;9(3)

56. van der Loo RP, van Gennip EM, Bakker AR, Hasman A, Rutten FF. Evaluation of automated information systems in health care: an approach to classifying evaluative studies. Comput Methods Programs Biomed. 1995;48(1-2):45-52.

57. Brender J. Evaluation of health information applications--challenges ahead of us. Methods InfMed.2006;45(1):62-6.

58. Ammenwerth Elske, Gräber Stefan, Bürkle Thomas, Iller Carola. Evaluation of Health Information Systems: Challenges and Approaches. Medical Informatics in Obstetrics and Gynecology.. Hershey, PA, USA: IGI Global; 2009. p. 330-345.

59. Kaplan Bonnie, Duchon Dennis. Combining qualitative and quantitative methods in information systems research: a case study. MIS Quarterly. 1988:571-586. 